\title{
On hotel service quality improvement
}

\author{
Qi Jun \\ Chongqing Institute of Engineering, Chongqing China, 400037 \\ qj_qi@126.com
}

Keywords: Hotel; Service quality; Improvement; Innovation

\begin{abstract}
Hotel service is one test for hotel (tourism) major students' comprehensive qualities. Hotel (travel) students can only better improve their comprehensive quality and ability in hotel service field, and ultimately contribute talents to the improving of hotel service quality. This paper carried on a shallow exploration from several aspects such as the scope of service idea, hotel service, hotel service, hotel service monitoring and so on so that students may continuously improve professional quality in hotel service quality promotion actions.
\end{abstract}

\section{Introduction}

The discretion of hotel service quality not only reflects hotel (travel) students' professional skills, but more reflects their comprehensive quality. In order to help hotel (travel) students improve their quality of hotel service professional theory knowledge, professional skills as much as possible in the process of hotel service work during internship. By effectively use externalization and self-restraint, unceasingly improve their comprehensive quality and service level. The author made elementary exploration on how to improve hotel service quality in order to promote the hotel professional students further improve professional practice ability and comprehensive quality in hotel service internship activities. The promotion of hotel service quality is of four points: change hotel service concept, develop new scope of services, adopt new service and new monitoring path.

\section{Hotel Service Concept Must Have New Connotations}

To increase hotel service quality, the first thing is to keep pace with the Times, take new service concept, change traditional service concept with an open mind and perspective solation, constantly enrich the content of new connotation. To this end, first research service object, according to customers' professional, cultural level, grade analysis such as the level of needs and tastes. Different hotel has various objectives, focus and levels of service, such as some hotel guests mainly are experts and scholars of education system, some hotels customers are mainly government officials, some are mainly businessmen. Obviously, different profession and industry background require different service demands. Based on the research of main customers located hotel, on the basis of regular service quality in eating and sleeping, enrich service concept with new content elements. One is to make image service element. Hotel's good service image will leave a good first impression on the guests, let guests produce goodwill in deep heart, and make a sense of "home". To this end, the overall layout of hotel must have an overall consideration and design, as much as possibly fuse coordination and beautiful image elements, from static to dynamic, from hidden inner world to visual appearance of image element. Reveal a kind of harmony and beauty. Two is to enrich the spiritual and cultural elements. In present material wealth, guests also show the trend of increasing demand of spiritual culture. Hotel service industry should intensify efforts to provide spiritual and cultural services to the guests to meet spiritual and cultural demands, which is also the trend of the Times. To this end, follow up on the relevant supporting facilities, provide information, and establish the corresponding functional areas, such as open wireless network, home theater, entertainment newspaper, current politics, etc. Three is to enrich health service elements. Health is the desire of the guests of all types and at all levels. The renewal of hotel service concept should also keep up with the pace undoubtedly. Provide guests with both healthy and comfortable environment, popularize the 
knowledge of healthy life, and at the same time provide timely help and services when there is a health problem. Equip the hotel with doctors or clear disease treatment channels, for example, psychologists to deduct health service elements.

\section{Hotel Service Scope Must Have New Objects}

Guests are the God of hotel. To develop or have a place in the same industry invincibly, hotel must expand the scope of services and develop new customers on the basis of retaining old customers. Retain old customers, and never forget my old friends. A variety of ways can be taken, such as ascend a return visit to typical customers, cooperation unit, or send SMS, telephone greetings during holidays, or invite them to participate in social activities so as to improve the friendship, let old customers understand hotel's new policy initiatives, and retain old customers with emotion. As to broaden the scope of service, develop new customers and attract new customers, the following measures can be taken:

One is to spread the hotel reputation in wider range, and let more customers have more choices with the help of diversified media to widely publicize hotel basic information and its service characteristics such as basic effective promotion propaganda techniques and modern Internet propaganda platform like television advertising, newspapers and billboards at dock or station and so on.

Two is to take going out strategy. On the one hand, target to sell. After investigation and study, actively promote the hotel for active units' "foreign affairs", and expand new business scope; Furthermore, take the initiative to contact travel company, and discuss cooperation, which is also a good way to expand their business; By send someone out to attend a series of hotel industry system communication seminars or other forms of series activities related to the industry, set up image in the industry, expand the influence, achieve the purpose of attracting new customers and make new friends.

Three is to take passing-on-experience strategy. By establishing preferential reward mechanism, encourage customers to introduce new customers to the hotel, and enlarge customer team in the form of snowball growing.

Of course, to retain old customers and attract new customers, "marketing" approach is important, but the vital interests of customers and hotel consumer prices and quality of service are the true touchstone and powerful magnet. So, hotel of a variety of consumer prices should carefully examine, and serious study to really let hotel guests feel good value and real; At the same time, ensure that guests receive the same quality of service. Only in this way will the hotel be relatively stable and even have growing team of customers and reveal a strong vitality.

\section{Hotel Service Way Must Take New Moves}

Hotel service has a close relationship with the level of service quality. Improving the quality of hotel service must keep pace with the Times, follow certain basic principles, and adopt new measures to ensure service, law-abiding business by chapters, and embody innovations with its own characteristics.

Hotel service should follow certain basic principles. The first principle is that customer comes first, which is the primary basis of service way based on the needs of customers. As far as possible on abundant service content, take care of the needs of different customers, and implement differentiated service; in the mode of service from service categories, operation flow and so on, each link takes customer need as guidance. Benefit maximization principle, that is, on the choice of service mode on the basis of guarantee the basic services quality, as much as possible on the added value maximize function of hotel services; this requires that the choice of service ways must also be integrated elements of the new era, reflect health civilization culture, and elegant note. The principle of lawful service methods, which is the hotel's service contents, must undergo and withstand the test of national laws and regulations. Both reflect period flavor, fully meet customer needs, and do not violate 
national laws and regulations. Under the law of the country, win customers with characteristics, and show strong vitality on its own real service. Continuously optimizing principle, that is the hotel service contents, service mode are not static, but according to the requirement of the society and the needs of the customers and their own development, the actual reasonable adjustment service content, innovation service mode always highly agree with the Time.

Reveal new measures on service mode. Following the framework of the basic principles, on the basis of inheriting the past good practice, the following new measures are mainly adopted. One is that new move should be made on the front desk service mode, make it convenient and at home. In order to let the guests have convenient and quick hotel formalities and check-out procedure, try to avoid the complex adverse situation. On the service mode, reform the past tradition, update or add advanced modern equipment to front desk service facilities, such as add check-in and check-out electronic window for guests in the hotel front desk or through the network system in advance. At the same time it can also be convenient for guests with the help of network online banking system to checking out. The front desk service measures innovation should adapt to the at home feeling. At the front desk, the service is the window of hotel image, and let a guest feel at home. One is to make front desk service a team of comprehensive quality and good temperament image. Intensify training, enhance their own hematopoietic function, moderate and introduce new personnel, and enrich fresh blood. In the service process, let a guest not only have a kind of sweet feeling from the appearance of this team and silent language, and in specific service activities, produce the feeling of "home". Therefore, play the role of the greeters, and it is necessary to add mobile personnel posts for convenient pick-up for the guest or put salute, really let them "back home". Second, scientifically define the front desk service personnel responsibility, both with basic specification requirements, and reflecting their intelligence and personality characteristics display space to really let guests feel "at home".

Moreover, take new moves in room service on the way. One is to enhance room service's safety consciousness, and let guests feel safe and secure. On the one hand, various forms to promote the guest to enhance safety awareness, such as by means of elevator, corridor, publicly play video propaganda, or room service personnel's proper reminding words, or safety warnings in guest room, on the other hand, pay special attention to the security service itself as an important part of room service, for example, contact guests whose valuables are left, lock the door in time, and ensure floor attended 24 hours and are equipped with security, camera probe system and so on. Second, focus on customer needs at any time to achieve satisfied service. On the one hand, keep perfect and smooth internal communication network. Help the guests with temporary special difficulties with the contact with room service personnel in a timely manner. Room service personnel, on the other hand, must be good at seizing the right time to capture guests' needs, for example, observe what guests worry or have other difficulties from the aspects of expression asana and ask properly to meet the guest irregular needs, such as buy golden voice HouBao or other articles for daily use on behalf of the guests whose throat is uncomfortable or provide mobile phone charger, etc. At the same time, open the remote functions of guest room machine, which would be convenient for guests to get in touch with his family, and let guests reduce cell phone calls with family of "high consumption".

The restaurant service is an important component of hotel services. In the mode of service, it also needs to keep pace with the Times. One is to constantly improve their own quality in the food, not only the number and types of the food, also pay attention to nutrition. Recommend meal nutrition formula for the guests, and let guests have scientific and rational diet according to their own physical condition to eat with quality and health. The second is to make added value of service in the restaurant, for example, meticulously make overall layout, placing of dining-room, food collocation with color, smell and taste, its staff, guides and other kinds of personnel etiquette image, and let guests have a pleasant mood and good appetite while entering restaurant.

\section{Hotel Service Monitoring Must Have a New Path}

Monitoring the process of hotel service is an important link in improving the quality of hotel service. In the past, many hotels ignore or belittle this link in the management process, which affects 
the quality of hotel service and avoids the forming of good reputation. Take new measures, expand new path, and strengthen hotel service activities and its link by monitoring the process. These are very important to improve the quality of hotel service. First, carry on the effective monitoring of service content. On the one hand, make the hotel service content meet the needs of the guests. On the other hand, provide services within the framework of laws and regulations, which is not unprincipled and unconditional. For example, some guests put forward some erotic aspects which are beyond the service content principle, or requirements to provide drugs.... In the face of such unreasonable demands and needs, there are a few hotel service personnel meet the needs of the guests for personal interests loss principle in private and damage the reputation of the hotel and the whole industry. Through timely and effective monitoring, timely discover and eliminate these phenomena. It can promote healthy development of hotel industry, and maintain its good image. Second, hotel service specification shall be monitored. No specification, no quality at all. Therefore, each link is necessary to be monitored all the way including hotel front desk, guest room, restaurant service in order to avoid bad things. Problems in the service specification shall be timely rectified, and provide good service impression in customers mind each step from beginning to end in all departments.

Moreover, security monitoring in hotel service system cannot be ignored. No security, the hotel has anything. Security monitoring is the most important in the entire hotel service system, and must be paid special attention to. On one hand, there should be regular and irregular inspections and update of safety facilities in hotel service system; on the other hand, synchronize monitoring on hotel service activities security, and put an end to all the unsafe factors of service activities. Finally, clear security feedback channels, and establish safety feedback mechanism, so as to fully collect relevant information in a timely manner, accurately grasp the dynamic safety state, and ensure the security of hotel service.

\section{References}

[1] Xu Shengnan. Business hotel guest satisfaction investigation and problem analysis [J]. Chinese Market, 2013 (37).

[2] Fan Linsheng. Hospitality industry value value innovation evaluation [J]. Journal of Front, 2013 (14).

[3] Wang Suzhen. Hotel service quality improvement strategies based on emotional satisfaction of customers [J]. Journal of Standard Science, 2013 (8).

[4] Wang Hui. "People-oriented" concept's application in modern hotel operation and management authority [J]. Journal of Modern Business, 2013 (29).

[5] Wang Yanrong. Hotel service and management professional practical teaching effectiveness improving strategy analysis[J]. Science and Technology, 2013 (05).

[6] Cui Wei. Hotel economic benefit promotion strategy analysis [J]. Modern Commercial and Trade Industry, 2013 (20). 